\title{
Citizens or Customers? Transit Agency Approaches to Community Engagement
}

\author{
Gerard C. Wellman, Ph.D. \\ California State University, Stanislaus
}

\begin{abstract}
Aristotle, in his work Politics, expressed his view that a citizen attains his or her fullest humanity by engaging in the work of the government by accepting ownership of the policymaking apparatus of the work of the polis. Such a perspective contrasts with those who consider citizenship to be merely a legal status, unconcerned with the affairs of the public and passive recipients of government services. This research considers what public administrators at mass transit agencies say they do in pursuit of engagement with their communities. The decisions that public administrators in transit agencies make regarding service retrenchment or expansion have deep, profound consequences on poor and vulnerable transit-dependent populations. Such transit administrators exercise a great deal of power over their ridership's lives since agency decisions have real-world consequences. Therefore, it is a critical research question to examine the methods, techniques, and underlying rationale of transit administrators' pursuit of community engagement. This research finds that public transportation agency approaches to community engagement can be typified into two broad perspectives of how the agency views individuals in their community: Community as Citizens and Community as Customers.
\end{abstract}

\section{Introduction}

Mass transit in the United States provides many opportunities for community enrichment and development. As a public service and utility, it provides access to quality-of-life issues, including access to healthcare, cultural institutions, education facilities, and employment opportunities. Public transportation also has the potential to alleviate societal ills such as environmental degradation, traffic congestion, the regressive nature of the cost of private vehicle ownership and maintenance, and the physical isolation of the young, older adults, and persons with lower incomes (Lutz 2014). Therefore, public transportation in the United States is an indispensable component of community development and social improvement efforts. 
How transit administrators engage their ridership and local communities in the agency's policy- and decision-making processes varies significantly among agencies. While required by Title $\mathrm{VI}$ to undertake some form of community engagement and public participation in agency decisions, how that is defined and operationalized is largely left up to individual agencies. Naturally, therefore, community outreach exists across a broad spectrum. Drawn from interviews with 30 transit administrators across the United States, this research categorizes their community engagement efforts, which will assist the reader in better understanding the extent to which mass transit agencies are actively involved in sustainable community engagement in urban areas.

\section{Citizenship and Community Outreach}

The United States' federalistic system of governing is arguably designed to reflect and create an active, involved citizenry that contributes to the policies governing them (King, Felty, and Susel 1998; Triplett 2013). What King and her coauthors (1998) term "administrative legitimacy" depends wholly on accountability of citizens to respect and adhere to basic values such as transparency and democratic governance; administrative states are legitimate when they are responsive to active citizens. The term "citizen," as embodied in such a perspective and throughout this article, does not refer to a legal status bestowed upon selected individuals (for example, those born in the United States or who moved here legally); rather, it refers to joining "each other in making decisions where each decider respects the authority of the others, and all join in obeying the decisions ... they have made" (Pocock 1995, 31). Citizenship, also called democratic citizenship, can be seen as engaging in the work of the public, seeking to benefit all rather than a powerful few. De Tocqueville terms this "self-interest properly understood" (1969, 526-627) whereas Denhardt and Denhardt (2011) succinctly describe democratic citizenship as "a way of life that involves a commitment to the community and to its members, a significant level of involvement in public affairs, and an occasional willingness to put one's own interest below those of the broader society" (47). In this tradition, a citizen is simply an individual actively engaged in the policymaking procedures of public agencies and institutions, and, indeed, can be accomplished by individuals who do not possess traditionally-recognized citizenship documentation.

When the administrative state is gathering citizen feedback from such citizens, democratic theorists assert that public trust in their institutions will rise (Halvorsen 2003; Shipley and Utz 2012); when administrators engage the public in a "dialectical exchange" (Fischer 1993, p. 183) or in bidirectional discourse (Fox and Miller 1995), they are truly reflecting democratic values. This implies that agencies seeking public input must allow that input to guide decision-making; "a history of participation with no visible impact on agency decisions can be worse than no participation at all” (Halvorsen 2003, p. 540).

Participation in this context is ineffective and conflictual, and it happens too late in the process - that is, after the issues have been framed and most decisions have been made. Therefore, rather than cooperating to decide how best to address issues, citizens are reactive and judgmental, often sabotaging administrators' best efforts. Administrators are territorial and parochial; they resist sharing information and rely on their technical and professional expertise to justify their 
role in administrative processes. Citizen participation is more symbolic than real

(King et al. 1998, 320; Arnstein 1969).

Therefore, a democratic model of public participation envisions administrators as liaisons between administrative issues and the public, using public feedback to shape responses to public problems (King et al. 1998; Patten 2001) and allowing citizens to, in essence, govern themselves (Box 1999). However, true dialogue is bidirectional (Fox and Miller 1995; O'Connor et al. 2000), and therein lie opportunities for administrators to use information to shape participants' beliefs regarding challenges and opportunities for the public agency itself (Halvorsen 2003; Triplett 2013). This research presupposes that community involvement in public transportation agency decision-making is a vital component of democratic governance, and this view has been shared, at least partially, by the framers of the 1964 Civil Rights Act and its Title VI stipulations.

\section{Title VI and Community Involvement}

Among the Title VI requirements for transportation agencies receiving federal funds are that the public be involved intentionally, that the community's concerns are taken under advisement by administrators, and that minority populations are included, and even targeted, for agency feedback (FTA 1999). Such community involvement is achieved, at least partially, through stipulations requiring that agencies hold a series of meetings with members of affected communities every time a major route or fare change occurs. Such provisions do not specify the types of meetings required but do necessitate advance notice of the meetings and, to some degree, where the meetings can be held.

What Title VI requirements do not stipulate is the amount of community feedback that is required to identify such changes. For example, ridership or farebox recovery ratios on a route that decline below a certain threshold may automatically be presented by agency staff as a route or corridor in need of restructuring. Reliance on quantitative data, in this case, rather than community input triggers required public meetings, which occur after changes have already been proposed. Thus, it is legally left to the agency to determine what changes-route, fare, or otherwise - to make, so long as affected communities are provided advance notice and opportunities to comment before the changes take effect. In spite of a democratic normative theory of citizen involvement, there is no requirement to allow members of the public to propose service changes or that agencies seek their involvement prior to proposing service changes.

Under Title VI guidelines, agencies are left to a "justifiable" standard to explain the level of community involvement they seek on proposed transit service changes; that is, if they can justify that changes were made to which the community did not object within a specified period of time, then the changes will likely receive Federal Transit Administration (FTA) approval. As one interviewee in this research stated, "Title VI does not rule the day. We've got a four-inch thick [interagency] policy manual that we adhere to." FTA Circular 4702.1A on Title VI compliance states, "Recipients and subrecipients have wide latitude to determine how, when, and how often specific public involvement measures should take place, and what specific measures are most appropriate" (FTA 2007, p. IV-5, emphasis added). 
It can be surmised that, short of the requirement that public transportation agencies seek community feedback and that such feedback be justifiably sufficient, transit operators are left with wide latitude to define, engage in, and pursue stakeholder involvement in their services. A wide variety of approaches to community involvement can be evidenced by the different approaches undertaken by agencies in this research, with resounding implications for democratic governance.

\section{Methodology}

Qualitative research presents a prime opportunity for analyzing and reconstructing perceptions of public engagement in public transportation decision-making for several reasons. Harding (1987) points out that qualitative research is better-suited for examination of problems such as mobility faced by women, minorities, and those with lower incomes because, like the transit agencies' outreach methods under scrutiny here, it allows for a deeper analysis of individual thoughts, does not discard outliers, and actively listens to all the voices that contribute. Further, as suggested by Hedges and Duncan (2000), qualitative research is invaluable to public sector research because of the richness of dialogue it can facilitate. The type of dialogue used in semi-structured interviewing, just as in citizen participation, is bi-directional and multi-faceted.

Using semi-structured interviews, this research focuses on what transit administrators say they do in pursuit of citizen engagement in agency decision-making. To answer this research question, 96 public transportation agencies were selected from the Integrated National Transit Database Analysis System at Florida International University. Criteria for inclusion in this study were that the agencies must be in metropolitan areas whose population is between 500,000 (on the assumption that many metropolitan areas smaller than 500,000 people frequently lack the resources necessary to maintain a robust transit system) and 4 million (on the premise that transit operators in very large metropolitan areas may face complicating, multifactorial hindrances beyond the scope of this research). Of the 96 United States transit agencies that meet these criteria, potential participating agencies were randomly selected via an Internet-based random numbers generator to create a geographically-representative sample. After identifying the transit agencies, high-level administrators were asked to participate in interviews on the basis of their job function or participation in prior academic research or through an expressed interest in community engagement. Of the 96 agencies meeting these criteria, 46 were contacted for interviews, of which 16 declined and 30 participated. Participating interviewees' job titles largely included CEOs, Executive Directors, Assistant General Managers, Chiefs of Operations, Directors of Administration, and Assistant General Managers, among others. Having insight into the administrative functions, planning, and vision of the agency was a requirement of interviewees. Interviewees were overwhelmingly male (74\%) and Caucasian (80\%). While Caucasian males accounted for slightly fewer than two-thirds of all interviewees, unfortunately, no specific effort could reasonably be made to include members of minority groups since a representative sample of transit administrators in the United States was desired.

In accordance with Institutional Review Board guidelines, participants were promised confidentiality and anonymity prior to participating in the research interview. Woods 
and McNamara (1980) found that confidentiality and anonymity encouraged openness, accuracy, and honesty. Further, because of the requirements of FTA through Title VI, a few questions of the interview could affect the interviewee's agency compliance with Title VI; therefore, interviewees' names, locations, or employing agency names are not disclosed below.

Agencies represented by the interviewees span all regions of the United States, with a predictable greater representation of more populous states and regions. Interviewees' metropolitan areas ranged from just over 500,000 to 3 million in population, and their agencies' annual operating budgets saw a similar wide dispersion from $\$ 11.3$ million to $\$ 320$ million. Interviews with participants primarily occurred over the phone (27), and three occurred face-to-face; all occurred solely with the author of this research. Interviews were recorded, transcribed, and hermeneutically analyzed using MaxQDA software.

\section{Findings}

Community outreach is undertaken by every transit agency in this research, with some agencies reporting Title $\mathrm{VI}$ compliance as their motivation and others claiming to seek transparency and stakeholder involvement. Naturally, such outreach exists across a broad spectrum with various approaches, definitions, and philosophies about whom the targets of such outreach should be, what should result, and, of course, how it should be done. This research categorizes the types of community outreach by transit agencies into two broad categories based on the perceived motivation for seeking to engage members of the public: 1) "Community as Citizens," in which the transit agency seeks input, feedback, and direction from the community; and 2) "Community as Customers," in which the administrators seek to build local rapport to grow the agency's choice ridership or to tend their community relations with those who do not use their services but may still have the opportunity to vote on a transit bond or tax levy. As is discussed below, the differences between these approaches revolve around how transit administrators perceive the "public" they are seeking to engage.

It is important to note, however, that there are specific outreach activities undertaken by agencies in this research which, while the administrators interviewed considered them community outreach, could more accurately be classified as benevolent community service. One Southern agency shared a service-minded, "good neighbor" approach to community outreach in which the agency partners with community health organizations to offer free AIDS testing, diabetes checks, nutrition consultation, and other health-based services at transit transfer centers. Two agencies, one Midwestern and Southwestern, operate free mini-libraries on board the agencies' buses, in which riders are welcome to take home books for free and return them on subsequent transit trips. Another Midwestern agency specifically seeks to hire non-violent ex-criminal offenders who frequently face difficulty finding employment after release from prison. This program is done in conjunction with local neighborhood organizations, and the agency has become a resource for those seeking to help returning ex-criminal offenders re-assimilate and reduce recidivism. Such examples of benevolent community service reflect a strong commitment to the agencies' communities. Thus, it should be clearly noted that the distinction between community service and community outreach is blurry in certain instances. 
Of the ways interviewees describe their agencies' community outreach efforts, 54 percent of specific activities mentioned in interviews are classified in this research as "Community as Citizens"-activities in which transit administrators seek effective community involvement in decision-making, priority development, and strategic planning. (The reader will recall that "citizenship," as described below, does not refer to a legal status, but rather engagement with public policymaking.) Such community engagement includes instances in which administrators view their community members as citizens exercising their right to govern themselves (Box 1999).

One East Coast interviewee illustrated this category through an exercise in which those attending public meetings were simultaneously asked to prioritize routes and corridors in which transit should be placed while learning about the limitations of the agency's budget:

[We did] "draw on the map" exercises where you give people ... a length of yarn, tell them the length of yarn equals a bus every half hour-so if you want to draw a new route that goes from point $A$ to point $B$ and you want it to go every 15 minutes, you've got to double up your yarn. Partly it's an exercise that makes people have to prioritize and understand budget constraints.... They understand that there is a trade-off between frequency of service, frequency and span of service, and geographic coverage. And you can only get so much with two yards of yarn.

A Western interviewee demonstrated the desire to mitigate political consequences that potentially could occur with transit expansions in certain neighborhoods.

On one corridor, in particular, that runs through largely minority or disadvantaged populations, we actually went out multiple times through the study process and attempted to contact every household in the neighborhoods directly impacted by ... both negative and positive impacts by this project.... [We] attempted to get information to every citizen, essentially "Here's websites in English and Spanish where you could get more information about our projects on our website, here's a map, here's where you can come. We'll have daycare, food, all of that at neighborhood meetings."

A Midwestern agency head directly contradicted common assertions that public meetings are held so that agencies can inform the public of their plans rather than elicit feedback from them: "Every time you go to these hearings, people will stand up and say, 'I don't know why I'm talking-you've already made up your mind.' And the interesting thing is that every time we've done this, we've never made up our minds."

A smaller West Coast agency goes "to transit centers, some of our bigger rail stations, and bus stations, and we set up a booth and try and get feedback about different changes or proposals there for passengers and it's actually been very effective."

Another West Coast agency perhaps represents one of the most comprehensive views of community involvement in projects by targeting certain neighborhoods for employee recruitment:

[The General Manager of the agency] recognized the fact that a number of minority groups were not happy with the results of past public works projects. 
So he set out to ... make the community a partner on [a new project], and the first thing he did was to hire individuals from the community, who had community ties and relationships.... [He] understood the value of bringing people in who have those community ties and have the ability to talk to the community and can really set up a community dialogue where the community feels like they're being heard and represented.

A Northeast agency undertook an exercise at a community meeting:

We give everybody in the room five sticky dots. You can put all five dots on one thing if that's the single thing that you want to see accomplished out of this route restructuring, or you can spread them around. We did that exercise 40 to 50 times at different neighborhood groups, tenant associations.

The unifying factor in each of these activities is the presumption that a portion of responsibility for decision-making rests upon the community. While professional administrators still exercise expertise, community groups and citizens are used in the decision-making process and given a voice in policymaking. Such a view of community as "governing citizens" contrasts with views in which community members are simply customers, or passive recipients of transit services, affected by-rather than affecting-transit administrators' decisions.

Within the "Community as Customers" category, accounting for 46 percent of interviewees' outreach efforts, are different perspectives on the value or purpose of community outreach. For example, outreach designed to educate the public on services offered or personal safety perhaps meets the perceived intent of the Title VI guidelines on community engagement; examples of "Community as Customers" below, however, occur without partnering with community members to create or change agency policy and contain few opportunities for citizens to impact agency policy, implying an administrative view of the community as customers awaiting service instead of empowered citizens shaping policy (Box 1999).

Outreach aimed specifically at increasing ridership and farebox revenue closely resembles private-sector marketing efforts. One Southwestern agency has "a team that does nothing but community and business development," which seeks to build "community relationships" with large employers to offer reduced fare to employees. A Midwestern transit agency illustrates the educational approach and operates a transit bus outfitted solely for community outreach.

When that bus goes out, it goes to schools, it goes to community groups. We talk about the [agency], how to use the [agency's transit services]. We talk about safety. It's an education program. We go to the schools, for example.... We teach kids on how to pay the fare, how to ride the bus safely. When you get off the bus, for example, make sure there's no traffic when you run around the front of the bus.

Some agencies' actions can be characterized by their desire to control the public's perceptions of the agencies. As an East Coast participant succinctly said, "The more we can educate the public about what we're doing and why we do things, the better off we are. 
If people understand what you're doing, there are fewer complaints and there's a better understanding when you have to make hard decisions."

Another East Coast interviewee similarly "had this thing called the 'Community Conversation,' and we're going literally everywhere anyone will listen to our story, whether it's a Rotary Club, [or] an Optimist Club."

A West Coast transit agency recognized the potential of its transit services to meet the mobility needs of a group of Vietnamese refugees:

We've used a variety of techniques to outreach to this community, including pictogram-type graphics that show the concept of what we're trying to advance, bringing in dedicated [language services] staff, meeting with community organizations and grassroots leadership to explain what we're doing, respond to questions, concerns, or issues that have been brought up by the community. [Also] meeting with them at community venues like their community center, which is where the soccer field is, and scheduling them to coincide with a major soccer game so there will be a lot of people from the community.... Just examples of that, of really getting in there and trying to connect to people at their level in their own language.

A Southwestern agency was direct in their community-outreach-as-marketing-efforts, saying, "We are currently trying to reach out to our Hispanic community because our Hispanic ridership numbers are not where we think they should be."

A Southeastern agency appears to bridge the gap between community outreach and outright customer recruitment with its travel trainer-staff who, if someone is new to the region or if he/she is new to public transit, actually will go out and ride the bus with the person, show him/her how to use the fare box, where to change buses, and so on, just to make them feel comfortable.

Many transit administrators in this research were extremely aware of the politics of their region and the political predisposition of area voters and tailor their community outreach accordingly. In many areas, voters, regardless of whether they use transit, participate in elections on tax levies and proposals to raise sales taxes to fund new transit projects. Because of this, transit administrators often find themselves in unique positions of trying to lead public agencies while simultaneously catering to constituencies and potential voters. Thus, about 10 percent of community outreach efforts discussed by interviewees are as much about reaching potential voters as reaching potential transit users.

A Midwestern interviewee illustrated the duality some administrators describe:

We're reaching out to all [people who vote] to show the value of the proposition.... We even go to places where we don't have service. [Outreach] is building community support, which helps because we have to go back to the voters every once in a while.... We have an ongoing building support in the community because we want to be the public organization in the area that has value, that provides value.... So that means you have to go out and tell people what you're doing. 
A Midwestern interviewee, in discussing where routes should be cut due to low ridership and farebox recovery ratios, alluded to a situation in which an underutilized suburban route would be spared at the expense of an urban one to mollify voters:

Even though ridership is really high [on the hypothetical route in the city], I take that route out, and I leave a route out in the suburbs that's got far less ridership. That's a political decision.... It can't be purely on the basis of [ridership]. You've got ... a political issue here because of the economics of the funding.

Similarly, a Southern agency meets "with neighborhood associations on a regular basis to talk about transit services" and attends "a metro council member's district meeting" in conjunction with elected officials.

In situations such as those described above, community engagement arguably emphasizes political considerations rather than service provision decision-making. However, as interviewees readily noted, this reflects the funding realities of many transit agencies in the United States.

\section{Conclusion}

Authentic public participation is a goal of many mass transit agencies in the United States. Community engagement in the "Community as Citizens" category provides administrative legitimacy, public accountability, and bidirectional dialogue that informs the public of the agency's needs and administrators of ridership's needs. "Community as Customers" represents a private-sector, New Public Management orientation to outreach in which the community and the agency's ridership are regarded as "customers" rather than democratic citizens and in which agency decision-making tends to be removed from active community engagement. Although increasing ridership and more effectively marketing transit services is certainly a worthy goal of transit administrators, it does not reflect the democratic intent of community outreach, nor does it fully legitimize transit services as a citizen-owned enterprise (Box 1999; Innes and Booher 2004; Patten 2001).

What can transit agencies do to ensure they are fully and completely engaging with members of their community and valuing their input as democratic citizens? This research yields a number of normative public participation recommendations specifically for transit agencies:

- Make public feedback and involvement a goal of the agency. Actively listen to community groups, neighborhood associations, or religious organizations to understand their community's transit needs.

- Engage local universities and academics in pinpointing needs and underserved communities. Many universities are looking for ways to partner with community organizations such as transit agencies, and such relationships rarely cost agencies money.

- Offer internships or other employment opportunities to youth from specific communities or high schools. Such an approach has yielded helpful results for agencies that have used it. 
- Use "draw on the map" or similar exercises at community meetings, which can facilitate bidirectional dialogue, both educating the public on the agency's constraints and identifying priorities of the public.

- Ask top transit agency officials and board members to use public transportation on a monthly basis to understand the mobility constraints inherent in most mid-size U.S. cities' transit systems.

High-quality community involvement by public transportation agencies is vital for both a functioning democracy and the legitimacy of transit agencies themselves. As this research shows, many transit agencies are actively engaging members of their community. While "Community as Customers" approaches to community engagement are necessary to attract ridership, reduce the stigma of transit usage in mid-size metropolitan areas, and improve farebox ratios, they should be used in tandem with vigorous engagement approaches that value public input and feedback in policymaking.

Transit administrators' decisions about service expansions or retrenchments can have profound consequences for when and how long-and whether-transit dependents can access important quality of life institutions such as education, healthcare, cultural, and employment facilities. It is imperative their voices be heard when their stake in the outcome can be life-altering. When robust methods of engagement from both "Community as Citizens" and "Community as Customers" are used, the democratic legitimacy of transit agencies will be realized, and transit users will have a voice in the policies that bear considerable consequences for their life chances.

\section{References}

Arnstein, S. 1969. A ladder of citizen participation. Journal of the American Institute of Planners, 35: 216-224.

Box, R. C. 1999. Running government like a business: Implications for public administration theory and practice." The American Review of Public Administration, 29(1): 19-43.

Cooper T. L. 2012. The Responsible Administrator: An Approach to Ethics for the Administrative Role, 6th ed. Jossey-Bass, San Francisco, CA.

Denhardt, J., and R. Denhardt. 2011. The New Public Service: Serving Not Steering, 3rd ed. M.E. Sharpe, Armonk, NY.

de Tocqueville, A. 1969 (1835). Democracy in America. Trans. George Lawrence. Doubleday, Garden City, NY.

Federal Transit Administration. 1999. Assessing Title VI capability - review questions. Retrieved from http://www.fta.dot.gov/civilrights/title6/civil_rights_11704.html.

Federal Transit Administration. 2007. Circular 4702.1A: Title VI and Title VI-dependent guidelines for Federal Transit Administration recipients. Retrieved from http://www.fta.dot.gov/civilrights/title6/civil_rights_11704.html. 
Fischer, F. 1993. Citizen participation and the democratization of policy expertise: From theoretical inquiry to practical cases. Policy Sciences, 26(3): 165-187.

Fox, C., and H. Miller. 1995. Postmodern Public Administration: Toward Discourse. Sage, Thousand Oaks, CA.

Halvorsen, K. 2003. Assessing the effects of public participation. Public Administration Review, 63(5), 535-543.

Harding, S. 1987. Introduction: Is there a feminist method? In Feminism \& Methodology, S. Harding, ed. Indiana University Press, Bloomington, IN: 1-14.

Hedges, A., and S. Duncan. 2000. Qualitative research in the social policy field. In Qualitative Research in Context, L. Marks, ed. Admap Publications, Oxfordshire, UK: 191-216.

Innes, J., and D. Booher. 2004. Reframing public participation: Strategies for the 21st century. Planning Theory and Practice, 5: 419-436.

King, C., K. Felty, and B. Susel. 1998. "The question of participation: Toward authentic public participation in public administration. Public Administration Review 58(4):317-327.

Lutz, C. 2014. The U.S. car Colossus: Pathways to the production of inequality. American Ethnologist, 41(2): 232-245.

O'Connor, R., M. Schwartz, J. Schaad, and D. Boyd. 2000. State of the practice: White paper on public involvement. Transportation Research Board: Committee on Public Involvement in Transportation, National Academy of Science: 38-45.

Patten, S. 2001. Democratizing the institutions of policy-making: Democratic consultation and participatory administration. Journal of Canadian Studies, 35: 221-239.

Pocock, J. 1995. The ideal of citizenship since classical times. In Theorizing Citizenship, Ronald Beiner, ed. State University of New York Press, Albany: 29-52.

Shipley, R., and S. Utz. 2012. Making it count: A review of the value and techniques for public consultation. Journal of Planning Literature, 27(1): 22-42.

Triplett, K. L. 2014. Increasing citizen voice in transportation related decision-making: A model for citizen engagement. TRB 2014 Annual Meeting, Washington, DC.

Woods, K., and J. McNamara. 1980. Confidentiality: Its effect on interviewee behavior. Professional Psychology, 11: 714-721.

\section{About the Author}

Gerard C. Wellman (gwellman@csustan.edu) is an Assistant Professor of Political Science and Public Administration at California State University, Stanislaus in Northern California. His research interests focus on public and active transportation, urban affairs, and social justice theory. He has recent publications in Public Administration Quarterly and Public Works Management and Policy. 